\title{
Chain of Firms Bankruptcy
}

\author{
Yoshi Fujiwara* \\ NiCT/ATR CIS Applied Network Science, Kyoto 619-0288, Japan
}

\begin{abstract}
A link in production network is usually a creditordebtor relationship. If a firm goes into financial insolvency state or bankruptcy, then firms on its upstream can have secondary effect from the bankruptcy. By using the recent 10 years data of bankruptcy in japan, we show that these causes of "link effect" are by no means negligible. Indeed, nearly $20 \%$ of total debt (a few percent of GDP) is due to such effect. Moreover, the link effect dominates, in probability, other causes of bankruptcy, such as poor performance in business, in the power-law regime of the distribution of debt when bankrupted. Because the production network has a heavy tail in degree distribution, and the effect due to bankruptcy chain is considerable in its ripple effect.
\end{abstract}

Keywords: production network, bankruptcy chain, power-law, econophysics

\section{Introduction}

Production network refers to a line of economic activities in which firms buy intermediate goods from "upstream" firms, put added-values on them, and sell the goods to "downstream" firms or consumers in the end of the line.

Consider an automobile manufacturer, for example. The firm buys a number of intermediate goods including mechanical parts, electronic devices, chassis and assembling machines, and produces cars. The manufacturer puts added-value on produced cars, in anticipation for return of profits, of course.

One of its upstream firms is a wheel manufacturer, which in turn buys intermediate goods including raw material of steel, aluminum etc. and fabricating machines. The wheel manufacturer may sell its products not only to the single automobile company but also to others, or even to other business sector such as train-vehicle manufacturer. On the other side, one of the downstream firms of the automobile manufacturer is a car retailer which sells its service to consumers.

The entire line of these processes of putting added-values in turn, therefore, forms a giant network of production ranging from upstream to downstream, down to consumers. Each process of

\footnotetext{
*yfujiwar@atr.jp
}

production also requires labor and financing as inputs. Thus, production, labor and finance are the three corner stones for all economic activities.

Net sum of added values in production network is basically the net total production, that is, GDP. Even if production network, its structure and temporal change are crucial in understanding macroeconomic dynamics, little has been hitherto studied about them. In this paper, we study a negative feedback on production network.

Recall that, in the above example, each firm attempts to put added value on intermediate goods and services in anticipation for return of profits anticipation, because no firm knows how their produced goods be actually demanded by downstream firms or consumers. In addition, many firms are facing uncertainty in the change of cost for goods produced by upstream firms (and also in the change of labor and financial costs). Therefore, only a posteriori, profits (sales minus costs) are determined through the interaction between a firm and its upstream and downstream firms.

Each link in such a giant network of production often represents a transaction based on a commercial credit contract. For example, payment by a firm to its upstream firms is usually scheduled in a following period but is not done instantly. Another case is direct lending and borrowing between subsidiary or collateral firms who are doing mutual transactions. Once a firm goes into financial insolvency state, its upstream firms are creditors who are not necessarily able to receive the scheduled payment. Then a creditor has its balance-sheet deteriorated in accumulation, and may eventually go into bankruptcy. This is a chain of bankruptcy, which we focus on in this paper.

One may think that such a chain of failure is a rare event and has limited influence. In this paper, we would like to show that chain of firms bankruptcy is by no means negligible. Indeed, total debt involved in chain of bankruptcy is typically $20 \%$, and occupies a non-negligible fraction of total GDP. Considering the number of creditors involved in bankruptcy occurred in those cases, we claim that this has a considerable effect to macroeconomic activity.

In the next section, we examine bankruptcy in the last 10 to 20 years of Japan, especially statistics on annual number and total debt of bankruptcy, ratio to GDP, and causes of bankruptcy. We show 

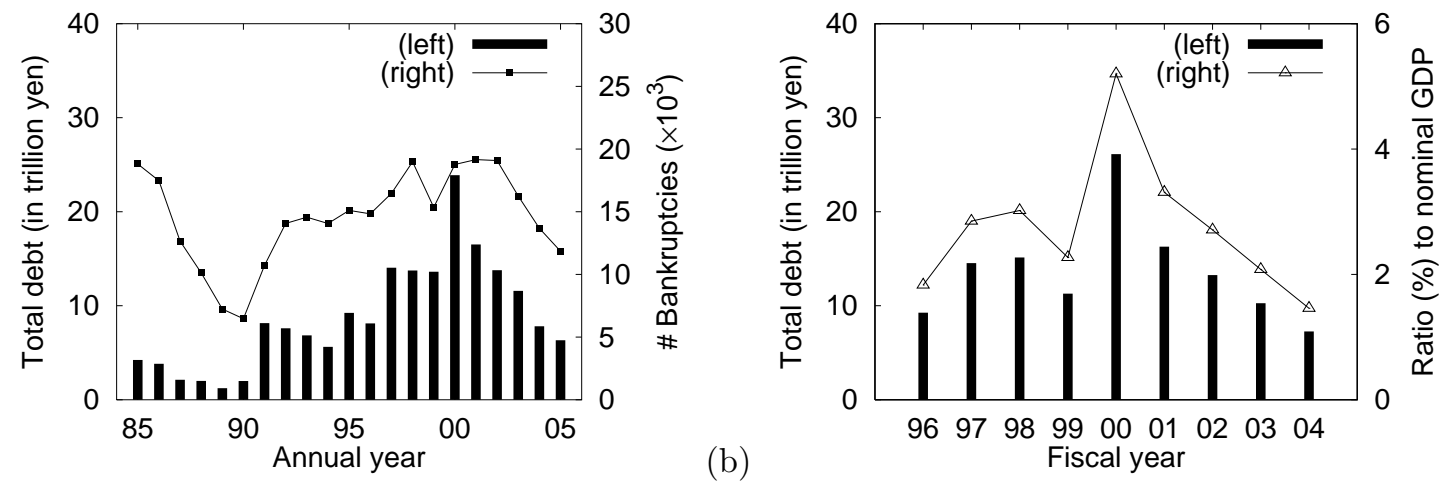

Figure 1: (a) Number of bankruptcies in each fiscal year from 1985 to 2005 (dots), and total sum of debts involved in them (in trillion yen, roughly equal to 7 billion euro; bars). (b) Total sum of debts in each fiscal year from 1996 to 2004 (bars), and its ratio to nominal GDP in corresponding years (triangles).

that chain of bankruptcy has a considerable effect in macroeconomics. In Sec. 3, we also show that production network has a long-tail in the distribution of degree, i.e. the number of nearest-neighbor firms in up and down-stream sides. This has a consequence of ripple effect, as we shall argue. We summarize in Sec. 4.

\section{Bankruptcy}

\section{number and debt}

Bankruptcy or business failure is not a legal term, but should be understood as a critical financial state of a debtor. Although formal classification according to different laws is given ${ }^{1}$, what is important for our purpose here is that most of bankruptcy cases are basically caused by financial insolvency state of the firm, that is, debt dominates its balance-sheet so that it has little fund in liquidity, and cannot manage business any longer.

Dataset that we use in this paper is the public resources given in [1]. The data originates from a japanese database company which has exhaustive data for cases with debt exceeding 10 million yen (roughly equal to 70 thousand euro), and additionally does investigation in its nation-wide branches for smaller-debt cases. The entire dataset thus covers essentially all cases of bankruptcy in japan.

In the last 10 years, the annual number of bankruptcy varies from 10,000 to 20,000 (see the dots in Fig. 1 (a)). The total amount of debts when bankrupted ranges from 10 to 25 trillion yen, roughly equal to 70 to 175 billion euro (see the

\footnotetext{
${ }^{1}$ Suspension of Bank Transactions, Internal Arrangement, Composition Law, Corporate Reorganization, Corporate Arrangement, "Bankruptcy", Special Liquidation. The most frequent cases are suspension of bank transaction, and more recently "bankruptcy".
}

bars in the same figure). The debt involved is quite large. Indeed, dividing the debt by nominal GDP in each year one finds the ratio typically equal to $2 \%$ or even more (Fig. 1 (b)). For the year 2001, the number is 19,991 , and the total amount of debt in bankruptcy is 16.28 trillion yen (roughly 110 billion euro), which amounts to more than $3 \%$ of GDP.

\section{causes}

Causes for each case of bankruptcy are investigated by the database company. The classification that is used by the company and is adopted in government statistics of [1] can be summarized as follows:

1. "solo" failure

(a) poor performance in business, which includes business depression, excessive competition and extrinsic shocks

(b) loose management, which includes failure of speculative investment, internal conflict and lack of efficient management

(c) accumulated deficit in long-term

(d) insufficient working capital

(e) accidental causes (disasters etc.)

(f) deterioration of products in inventory

(g) excessive investment in plant and equipment

2. "link" effect

(a) secondary effect from bankruptcy of customer, subsidiary or collateral companies and failure of business-related firms

(b) failure of accounts receivable

3. others

(a) refusal of credit by financial institutes

(b) unclassified 

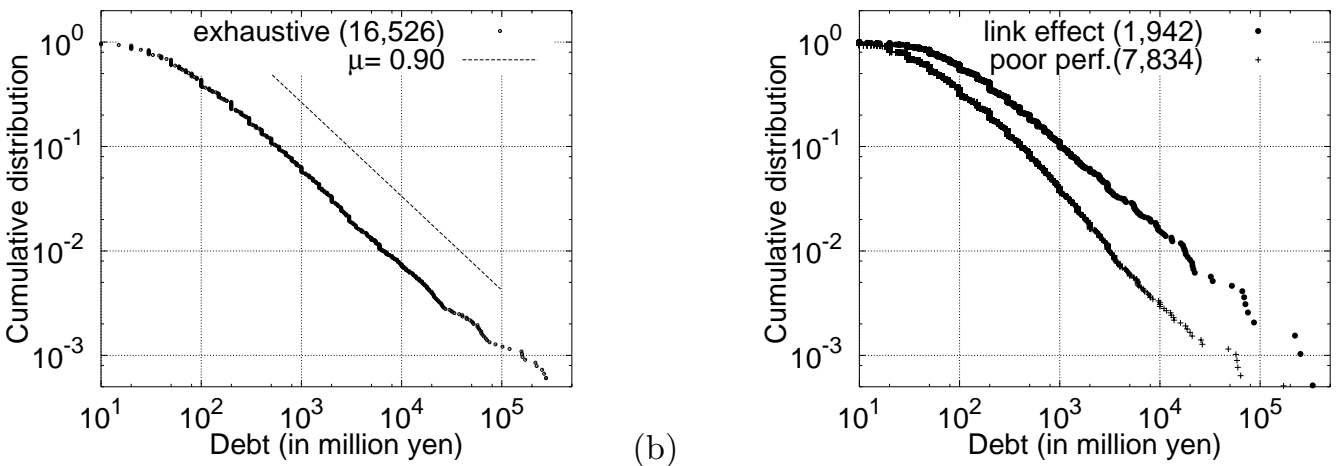

Figure 2: (a) Cumulative distribution of firms debt when bankrupted. The number of data amounts to 16,526 firms bankrupted in the year of 1997. (b) The same distribution conditioned on bankruptcy cause - "link" effect (cause 2) and poor performance (cause 1a). The numbers of cases are 1,942 and 7,834 respectively.

In the fiscal year 1997, for instance, each classified cases are, increasing order, 8,956 (1a), 2,724 (1b), $2,002(1 \mathrm{c}), 1,792(2 \mathrm{a}), 1,404(1 \mathrm{~d}), 373(1 \mathrm{~g}), 358$ (2b), 330 (1e), 210 (3a), 89 (1f), 8 (3b) with total number $18,246^{2}$.

The classification can be broadly divided into two groups. One group is basically poor performance in business and loose management, both of which are state of individual firm. The other group, in contrast, states the importance of link effect to other firms; direct influence of other firm's bankruptcy and failure of commercial credit contracts. Let us call these two groups as "solo" failure and "link" effect.

Link effect can be described plainly as follows. Transaction is often based on a commercial credit contract. Suppose a firm B buys intermediate goods from A. Payment by B to A is usually scheduled not instantly but in a following period. Thus transaction is usually based on credit contract. In other words, a business transaction is a linkage of creditor(A)-debtor(B). This is also true for direct lending and borrowing between subsidiary or collateral firms which are doing mutual transactions.

If $\mathrm{B}$ goes into bankruptcy or into financial insolvency state, the scheduled pay-back can be possibly not performed. If $\mathrm{A}$ were bankrupted in a later time, this process forms a bankruptcy chain, from B to A. Such a process is considered to propagate from downstream to upstream, along links of commercial credit contracts.

Question would then be how large such link effect is. Do they frequently occur or not? And how

\footnotetext{
${ }^{2}$ Classification is mutually exclusive. A bankruptcy can have more than one cause. Statistical weights are assigned to causes individually, and the cause with largest weight is recorded to each bankruptcy. We employ this this classification scheme.
}

does the effect depend on amount of debt when bankrupted? In order to answer these questions, let us first take a look at the distribution of debt.

\section{distribution of debt when bankrupted}

We employ an exhaustive list of japanese bankrupted firms in the calendar year $1997^{3}$. The data is exhaustive in the sense that any bankrupted firm with total amount of debt exceeding 10 million yen (70 thousand euro) is listed. The number of such firms in the year is 16,526 . Each case is classified in bankruptcy causes as described above.

Fig. 2 (a) shows the cumulative probability distribution of debt when bankrupted. For large debts exceeding $10^{8}$ yen, we can observe a power-law distribution over three orders of magnitude or even more. The probability that a given bankrupted firm has debt equal to or greater than $x$, denoted by $P_{>}(x)$, obeys $P_{>}(x) \propto x^{-\mu}$, where $\mu$ is a constant, called Pareto index for bankruptcy. $\mu=0.911 \pm 0.008$ (by least-square-fit for samples equally spaced in logarithm of rank in the powerlaw region; error is $90 \%$ level). See [2] for more.

Now let us compare the cumulative distribution for bankruptcy in the group "link" effect (2) with that for "solo" poor performance (1a) in Fig. 2 (b). We can observer that $\mu$ is different in the two distributions. Link effect has a longer tail, and has a higher probability in the same tail region. This means that the chain of bankruptcy takes place more frequently than poor performance failure in the power-law regime.

For example, in the fiscal year of 2001, the number for cause $2 \mathrm{a}$ is 1,731 in total. Interestingly, as the amount of debt when bankrupted becomes

\footnotetext{
${ }^{3}$ We remark that statistics [1] and accordingly other plots in this paper are based on fiscal years (April to March).
} 
larger, the number of these cases $(2 \mathrm{a}, 2 \mathrm{~b})$ is observed to be larger in fraction. In fact, the 208 bankruptcies with each debt being more than 10 billion yen, the cases of influence by other firm's bankruptcy is 62 in the number, while the cases of poor performance is 48 , even less.

We verified that this fact does hold for all the fiscal years we examined, from 1995 to 2004 by using tabulated data. Fig. 3 shows the cumulative distribution of debt for link effect and that for poor performance in the fiscal year 2004, for example.

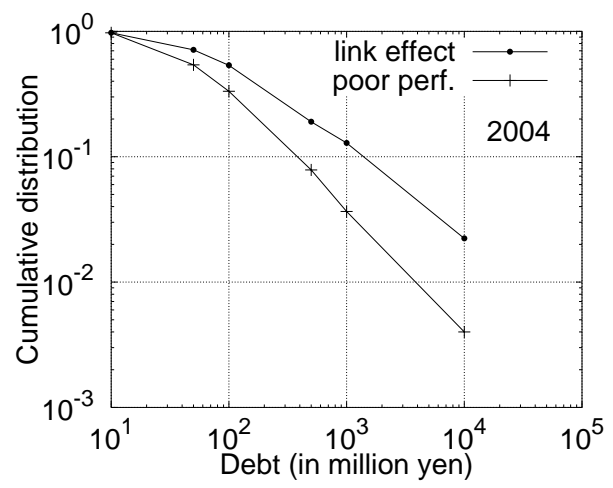

Figure 3: Same as Fig. 2 (b), for fiscal year 2004, compiled from tabulated data. Link effect (filled circles) and poor performance (crosses). The numbers of cases are 1,032 and 8,951 respectively.

Fraction of cases due to link effect is given in Fig. 4. While the fraction in number is typically $10 \%$, that in debt is about $20 \%$ in average. The fraction in debt is larger in the region of large amount of debt as we have seen so far, typically $20 \%$ to $30 \%$ (not shown here).

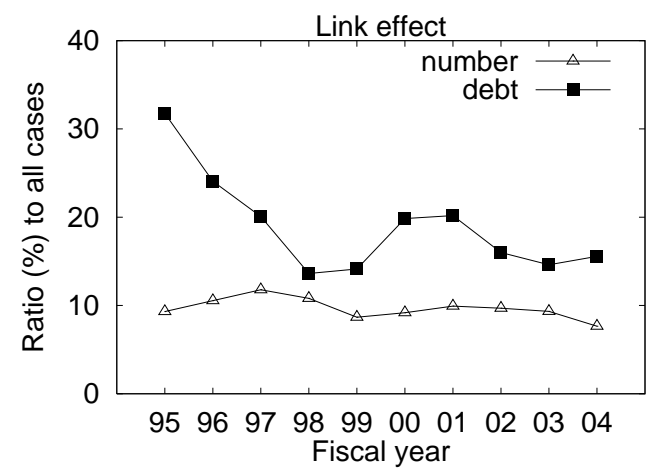

Figure 4: Fraction of cases due to link effect in all the cases. In terms of number (triangle) and of debt (squares).

\section{Ripple effect}

By looking at individual examples of bankruptcy, we can see that a bankrupted firm, or a debtor, has a large number of creditors in its upstream. This is basically because actual production network has a heavy-tailed distribution of degree, that is, the numbers of firms in upstream side and downstream side (see also [3]).

A sample is given below for a bankrupted retailer. The amount of debt borrowed by a bankrupted firm is largest for financial institutes as creditors. But the number of creditors is largest for non-financial firms.

\begin{tabular}{l|r|r} 
related to & number & debt (in $10^{3}$ yen) \\
\hline business $^{a}$ & 96 & $1,360,592$ \\
financing $^{b}$ & 12 & $3,393,976$ \\
\hline total & 108 & $4,754,568$
\end{tabular}

Suppose a firm A sells its goods to B. Payment by firm B to A, was not actually performed in commercial credit contract after the bankruptcy of firm B. The 65 cases of accounts payable in the table entry "96" are such firms (A) which are in upstream of the retailer (B).

Most vulnerable firms would be those who have a small number of links to sell products. Because a firm which has a single transaction, for example, would experience a critical insolvency state when the single firm in its downstream goes into bankruptcy. Among the 65 firms, one would be able to find such vulnerable firms on production network.

It is worth noting that the number 65 is large and is not exceptionally large. Actually, production network has a heavy-tailed distribution of degree, that is, the numbers of firms in upstream side and downstream side. Fig. 5 shows cumulative distributions of degree (left: in-degree, right: outdegree) for japanese firms (total number 23,490) in the year 2003. Here a directed edge or link is defined to be present from firm A to firm B, if A sells its product to $\mathrm{B}$ (equivalently, if $\mathrm{B}$ buys intermediate product from $\mathrm{A}$ ). In each plot, a power-law distribution $P_{>}(d) \propto d^{-\mu}$ is shown where the degree is denoted by $d$, simply as guide for eyes. Firms with the largest out-degree are trading and distribution companies which include Mitsubishi Corporation, Itochu and Marubeni, as well as manufactures which include electronics companies Fujitsu and Matsushita Electric (Panasonic). Those with the largest in-degree are the same those firms as well as automobile companies such as Toyota and

\footnotetext{
${ }^{a}$ For accounts payable (65), leasing receivables (12), deposits (11), expenses (7), other obligation (1), numbers in parentheses.

${ }^{b}$ From financial institutes (8), non-financial institutes (2), bonds (2), numbers in parentheses.
} 

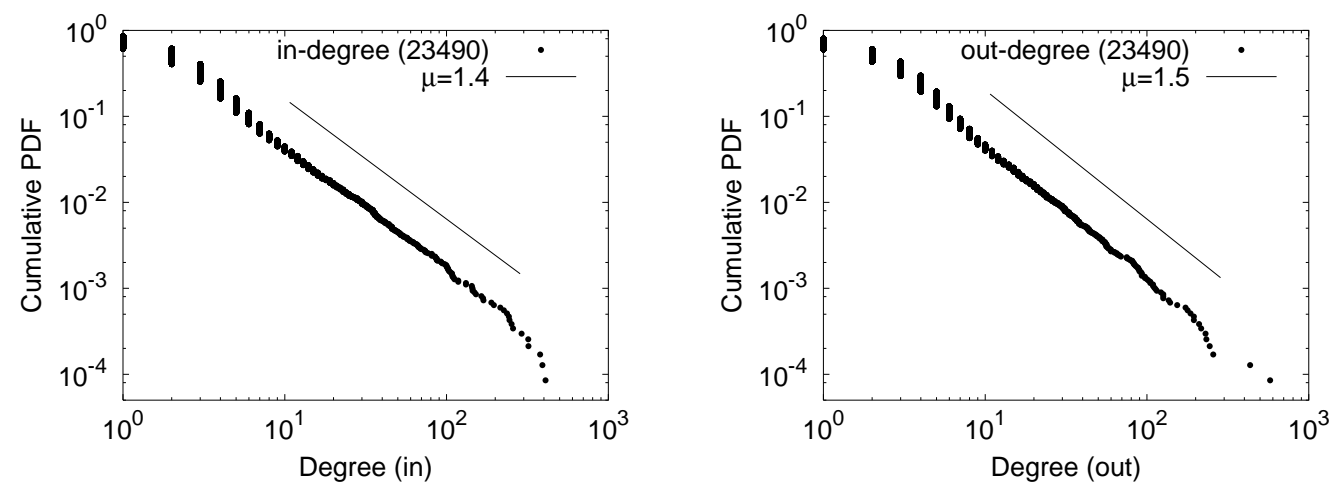

Figure 5: Cumulative degree distributions for in-degree (left) and out-degree (right). Here a directed link from firm A to B is defined to be present if intermediate products flow from A to B. The data is for japanese firms (total number 23,490) in the year 2003.

Nissan, and construction companies such as Taisei Corporation.

Because the in-degree distribution has heavy tail, one can expect not only that the number of firms in upstream by 1-link is large, but also that that by 2-link is larger than one can naively expect. Suppose that the average in-degree is 10. Although one may naively think that the number of firms 2-link away in upstream side is $10 \times 10$ or 100 (ignoring overlaps), the actual number is much larger because of the heavy tail (see in [4]). This implies that the total number of firms, which can potentially go into a worse financially deteriorated state due to a single bankruptcy in its downstream by 1 -link or by 2 -link, is quite large. See Fig. 6 for illustration, at the center of which is the retailer that corresponds to the bankruptcy instance given in the above table.

Therefore, even if the probability of finding a firm in financially critical state is not large, ripple effect can be quite large. We think that this is why chain of bankruptcy has a relatively large effect as we saw in the previous section.

\section{Summary}

In summary, by using the recent 10 years data of bankruptcy in japan, we show that the creditordebtor relation in production network brings about chain of bankruptcy, whose effect is considerable. Actually, nearly $20 \%$ of total debt involved in bankruptcy (roughly a few percent of GDP) is due to such link effect. We also show that the link effect dominates other causes of bankruptcy, such as poor performance in business, in the power-law regime of the distribution of debt when bankrupted. Because the production network has a heavy tail in degree distribution, number of involved firms in up- stream by 1 or 2-link is large, and the effect due to bankruptcy chain is considerable.

The author believes that it is highly desirable to analyze the entire of production network and to do monitoring and prediction on bankruptcy and default chain and its influence. This line of research would be a new direction and application of econophysics and network science.

\section{acknowledgement}

The author would like to thank Hideaki Aoyama (Kyoto University), Yuichi Ikeda (Hitachi Research Institute), Hiroshi Iyetomi (Niigata University), Taisei Kaizoji (ICU) and Wataru Souma (ATR) for discussion and sharing data, and Mauro Gallegati (University of Ancona) for giving some results of his model about bankruptcy chain. He would like to express special thanks to Tokyo Shoko Research, Ltd. for kindly providing partial information given in Fig. 6, and to SMRJ for correspondence and kind assistance.

\section{References}

[1] Organization for Small \& Medium Enterprises and Regional Innovation, Japan (SMRJ), Annual Report of Enterprise Bankruptcy.

[2] Y. Fujiwara, "Zipf law in firms bankruptcy", Physica A 337 (2004) 219-230.

[3] Y. Fujiwara, H. Aoyama, W. Souma, "Firms Growth and Networks", in Econophysics \& Sociophysics: Trends \& Perspectives, edited by B. K. Chakrabarti, A. Chakraborti, A. Chatterjee (Wiley-VCH, Berlin, 2006). 


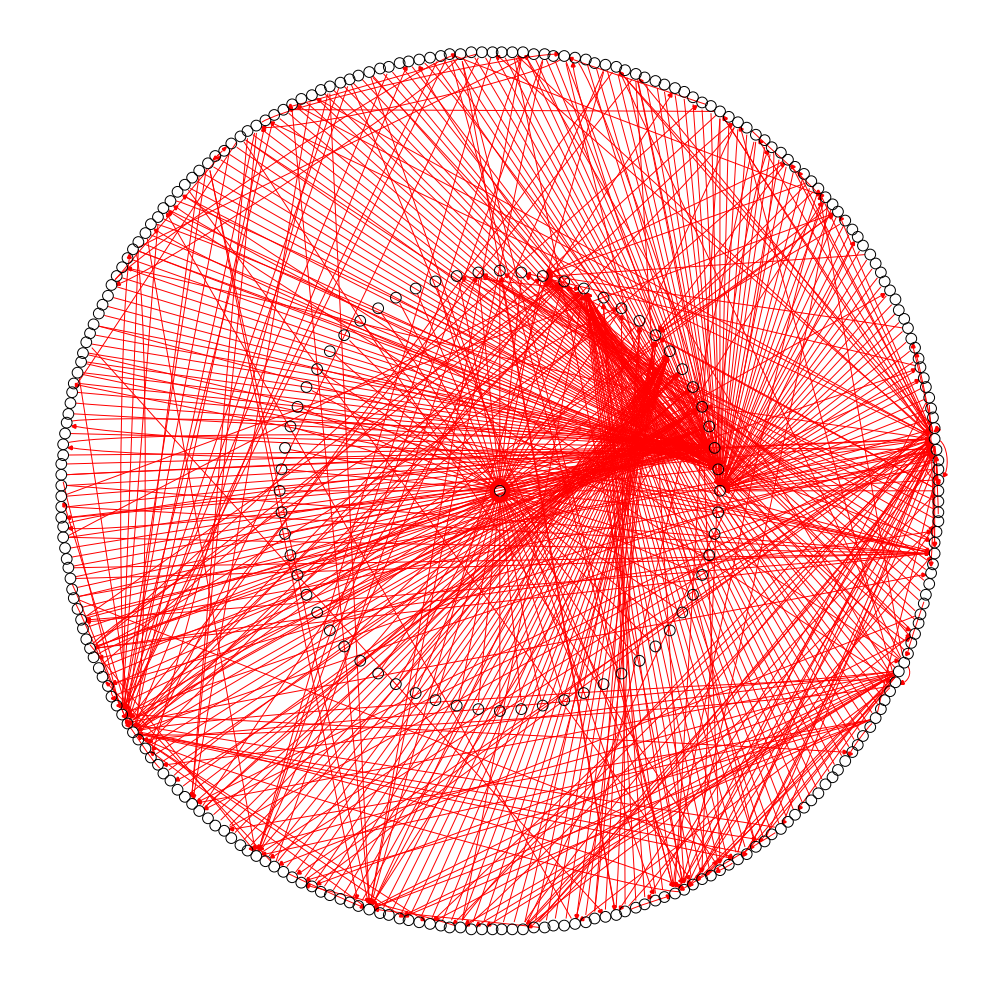

Figure 6: An example of bankrupted firm. The firm is a retailer which has many branches in a local prefecture, which is depicted at the center. The linked firms on the inside circle are creditors. The outside circle depicts their buyers and sellers in production network. Data is in the year 2005.

[4] M. E. J. Newman, "Ego-centered networks and the ripple effect", Social Networks 25 (2003) 83-95. 